\title{
Gestão desportiva e política pública na região metropolitana de Recife
}

\author{
Vilde Gomes de MENEZES* \\ Aurenéa Maria de OLIVEIRA* \\ Edílson Fernandes de SOUZA*
}

*Universidade Federal de Pernambuco.

\begin{abstract}
Resumo
Neste artigo reflete-se sobre a gestão de desportos desenvolvida na Região Metropolitana de Recife por meio da análise do discurso de gestores de 14 cidades que compõem essa área, sublinhando as percepções socioculturais destes que influenciam nas/em práticas desenvolvidas em torno dessas políticas. Para tal, trabalha-se com a metodologia da Análise de Conteúdo no sentido de examinar até onde vícios culturais interferem no desenvolvimento concreto de políticas públicas desportivas descentralizadas e comprometidas com o escopo de uma cidadania participativa.
\end{abstract}

Unitermos: Gestão; Política Pública; Desporto.

\section{Introdução}

Este artigo, recorte de uma tese de doutorado defendida em 2009 na Universidade do Porto em Portugal, de título Gestão de políticas públicas desportivas municipais: análise da região metropolitana do Recife-PE, Brasil, no período de 2002-2008, (MENEZES, 2009), tem como objetivo investigar a política pública desportiva da Região Metropolitana do Recife (RMR) por meio da avaliação dos discursos de gestores municipais. Assim, estabelecemos a análise tendo como meta dois aspectos implexos: o primeiro diz respeito à descentralização empregada pelos gestores de desporto das cidades que compõem a RMR. O segundo é verificar a participação popular nos processos decisórios das políticas de desporto naquela região, tendo por dimensão teórica, as contribuições de PUTtNam (2002).

No entanto, tratando do desempenho da gestão pública urbana de forma geral, diversos autores, como Andrade (1996), Azevedo (1996), Couto (1999), LeAl (1994, 1996, 2003), Melo (1996, 1999), Moura (1996), Lubambo (1999, 2000) e Menezes $(2002,2005)$ analisam os elementos reveladores ou desvendadores dos fatores singulares de gestão pública, bem como o respectivo impacto, tudo isso como decorrência do processo de descentralização; assim como G. PIRES (1993, 1995), Constantino (1999), G. Pires e Sarmento
(2001), Sarmento (2002) e Vieira (2004) de forma específica, tangencialmente falando.

Dessa forma, o processo de descentralização/municipalização é considerado, com base em experiências locais, um dos principais mecanismos de democratização do Estado e da sociedade e como instrumento de enfrentamento da exclusão social (LEAL, 1996).

Esse debate pode ser recuperado com a contribuição de Lobo (1990) e LeAL (1996) no que diz respeito a uma confusão conceitual e simbólica entre o conceito de descentralização e desconcentração, que aparecem como sinônimos em especial nos discursos e programas governamentais. Para esses autores, confundir os conceitos e aceitar a desconcentração como descentralização significa não considerar a possibilidade de se mexer com estruturas consolidadas de poder.

Assim, a avaliação em um cenário de mudanças e adequações constantes na agenda pública governamental - decorrentes do impacto da descentralização no Brasil no que diz respeito à atuação de entes subnacionais, notadamente os municípios.

Nesse sentido, os novos modelos de gestão, o perfil institucional e a atuação das administrações locais, para a efetivação do processo descentralizador, são particularmente as ações dos governos locais, resultado de engenharias políticas e de culturas políticas 
diferenciadas e heterogêneas, direcionadas a uma nova dinâmica na gestão urbana dos municípios brasileiros, que, em última análise, referem-se ao processo de redistribuição do poder e ao aprofundamento da democracia.

As razões que levaram diversos governos locais a empreenderem açôes avaliadas como "bemsucedidas" têm sido objeto de diversos estudos que procuram explicar de modo teórico e empírico esse novo fazer da administração pública local.

Então, quais as implicações, os limites e avanços decorrentes desses novos modelos de gestão urbana e do processo de descentralização para a consolidação da democratização da sociedade e do Estado brasileiro?

De acordo com ToBAR (1991), existe uma tensão entre centralização e descentralização na perspectiva da redefinição do papel do Estado na sociedade. No caso brasileiro, a Constituição Federal de 1988 prevê a obrigatoriedade de os governos federal, estaduais e municipais formularem e desenvolverem políticas públicas descentralizadas, impingindo, em particular aos governos locais, a incumbência de proceder à utilização de meios e mecanismos institucionais e políticos visando ao processo descentralizador, com o objetivo de estabelecer mais eficiência e efetivação no encaminhamento das políticas sociais.

Dessa forma, iniciativas louváveis indicam que, mesmo com as condiçōes adversas provenientes da descentralização perversa apontada por MELO (1997), várias experiências significativas encontramse em andamento no seio da sociedade brasileira. Melo (1997), antevê essa ocorrência quando afirma:

A experiência descentralizante num contexto democrático tem permitido, no entanto, um processo de aprendizagem social em que seus limites e possibilidades podem efetivamente ser compreendidos. A conjugação de reformas descentralizantes (que ocorre em escala global) e de uma crise do Pacto Federativo confere ao caso brasileiro singularidades que tornam esse país um rico laboratório de experiências políticoinstitucionais (MELO, 1997, p.138, grifo nosso).

Nessa direção, diversas elementos contribuíram para o fortalecimento dos procedimentos, das engenharias políticas e burocracias locais em um marco conjuntural e estrutural, e possibilitaram respectivas vicissitudes em um contexto de adversidade encaminhado à esfera institucional.

Os aspectos positivos do processo de descentralização no Brasil, no que se refere à efetivação de políticas sociais urbanas diferenciadas, inovadoras e resolutivas entre os governos subnacionais - decorrentes de processos de participação, deslocamento de poder e construção da cidadania ativa -, são uma realidade em diversas cidades brasileiras.

A recente questão da descentralização tem um imbricado muito grande com a agenda das políticas sociais de desporto no âmbito do debate sobre o papel do Estado. Estrutura e composição têm sido constantemente debatidas por parte dos governos, grupos de interesses, sociedade civil e estudiosos da gestão do desporto no Brasil e em países como Portugal e Espanha.

Os estudos de Moura (1996) e Viana (2003) mostram diversas evidências significativas que apontam a reinvenção no trato da coisa pública nas cidades, em especial, com a inserção do Programa Administração Participativa.

Assim, qual é a estrutura, quais são os mecanismos que coordenam a relação autonomia versus controle, ou seja, como a participação da comunidade se imbrica com a descentralização? Apesar dos limites e retrocessos, LEAL (2003) afirma que a descentralização no Brasil tem contribuído, de forma significativa, para a consolidação de uma cultura política que amplia e fortalece a cidadania, bem como a democracia. $\mathrm{O}$ espectro desse processo estaria ligado à inserção de setores populares da sociedade na definição da agenda pública governamental.

O fenômeno da descentralização, segundo Leal, estaria ocorrendo no mundo inteiro. Trata-se de uma arena diferente em que é possível que mais agentes possam ensejar e articular interesses coletivos sem apadrinhamentos, constituindo-se uma nova engenharia política das relações advindas da sociedade e da gestão urbana dos interesses da coletividade. Segundo LEAL (2003, p.25), “os modelos de gestão participativos são instrumentos de aperfeiçoamento democráticos, complementando, de certa forma, o sistema de representação política”. Essa lógica, do ponto de vista teórico, seria um marco, em que a relação entre governo local e participação democrática caminharia em uma espécie de "autogestão", que possibilita visualizar a multirresponsabilização resultante dessa simbiose.

LEAL (2003) afirma que os modelos de descentralização político-administrativa têm orientado as mais diversas experiências de gestão municipal, tanto nos países desenvolvidos como nos chamados países em desenvolvimento. Argumenta que a relação entre governo local, participação e democracia tem sido defendida como "corolário fundamental do aprofundamento democrático", sugerindo que estar próximo dos problemas locais pode gerar um 
sentido de responsabilização pública, efetivando-se, dessa forma, as questóes de autogestão e resolubilidade inerentes à demanda apresentada.

Os impulsos pró-descentralização se expandiram. $\mathrm{O}$ movimento desse processo identifica-se com o da construção de outro pacto federativo, sendo as seguintes razões para a descentralização, entre outras:

a) reaproximação e socialização das classes populares;

b) descentralização do poder político;

c) democratização das administrações públicas;

d) criação de condiçôes favoráveis para promover modelos mais equilibrados e adaptados às necessidades sociais;

e) possibilidade de evolução e do esclarecimento social com a ampliação da cidadania e do engajamento participativo.

Dessa maneira, da mesma forma que há muitos municípios prósperos que podem obter recursos de seus tributos e de outras fontes de receitas próprias, há também muitos municípios que não conseguem realizar o milagre de arrecadar o suficiente que lhes permita o desempenho de suas funções, tais como em desporto, lazer, saúde, educação limpeza e outras áreas. Sendo assim, a descentralização concebida como democratização do Estado requer a criação de mecanismos de representação como partidos, comissões, consulta, planejamento, conselhos gestores.

Como visto, o conceito de descentralização assume características multifacetadas, plurais, alcançando formatos altamente diferenciados. Segundo CASTRO (2002), a descentralização é o processo pelo qual se valoriza a ação pública, com o objetivo de maior resolutividade de atendimento às demandas das populaçōes via políticas públicas. De acordo com a autora, o Brasil tornou-se um país altamente descentralizado em comparação com outros países federativos, o que trouxe inúmeras mudanças nas relaçôes intergovernamentais e no poder relativo dos governos e das sociedades locais.

A teoria organizacional contemporânea também aponta para a emergência de um paradigma pósburocrático, que enfatiza estruturas horizontalizadas e cooperativas de governance em lugar de estruturas hierarquizadas (BARZELAY, 1992). A descentralização também tem sido advogada no quadro de valorização recente de formas de democracia direta e de mecanismos de controle social mais efetivo, para além das instituições representativas.

No caso das políticas desportivas, a centralização é evidente, uma vez que a maioria dos municípios sobrevive praticamente do Fundo de Participação dos Municípios (FPM), e o nível de empobrecimento é tão aviltante que sua prioridade não passa pelo fortalecimento do desporto local.

O principal constrangimento com a descentralização e com a prestação de serviços sociais está na disparidade inter e intrassetorial. $\mathrm{O}$ que demonstra a possibilidade implícita na literatura de que um "círculo virtuoso" seria estabelecido por políticas descentralizadoras e as virtudes se distribuem equitativamente. O caso do desporto no Brasil é bastante emblemático nesse sentido: a descentralização auferiu maior autonomia às entidades, e os resultados decorrentes da descentralização ficaram concentrados em algumas agências privadas de gestão do desporto.

O tema da participação cidadã e do "empowerment" no Brasil tem sido objeto de preocupação de diversos estudiosos filiados às Ciências Sociais, entre os quais, Valla (1998), Modesto (2005) e AвiB (2008). Seus estudos verificam o processo de participação e maior democratização do Estado, tendo como uma de suas vias o processo de participação.

Portanto, trata-se de um mecanismo com debilidade operativa, o que se constitui um custo para o processo de democratização das referidas políticas desportivas, como também no que concerne ao desenvolvimento de uma cultura cívica em termos de Putnam (2002).

No entanto, os governos locais têm aumentado sua participação na prestação de serviços sociais e se tornaram os principais provedores.

"Empowerment" da sociedade:

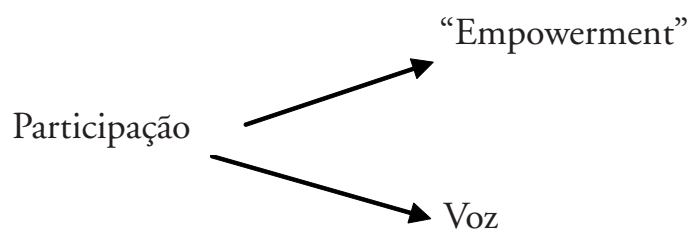

Participação - procedimento indutivo de reformas por políticas nacionais que permitirão às pessoas se associarem a organizaçóes não governamentais. Para a comunidade multilateral, a participação é uma forma de integrar os desorganizados, isto é, os pobres na chamada sociedade civil, criando a capacidade de influenciar (e não necessariamente de decidir) sobre questôes que lhes afetam diretamente.

Visão da participação como voz, e não como "empowerment” - mostra cautela em relação ao papel de cada instituição formal da democracia representativa. A noção de "empowerment" implica a tomada de consciência sobre injustiças e iniquidades, e, ao mesmo tempo, a crença nas possibilidades de ação coletiva para a promoção de mudanças. 
A participação como voz, e não como "empowerment", tem sido bastante utilizada no Brasil, estimulada por políticas nacionais, como recomendadas pelo Banco Mundial, que requerem a constituição dos chamados conselhos comunitários a fim de liberar recursos para a área Social (saúde, educação, assistência social e infraestrutura).

A obrigatoriedade de constituição desses conselhos pode significar, em muitas localidades, mera reprodução formal das regras do programa, ameaçando os fundamentos principais da participação: credibilidade, confiança, transparência. A "accountability" e o "empowerment" têm sido perseguidos por alguns governos locais.

Essa emergente cultura política teria por objetivo levar a ser estabelecido e ampliado o grau de participação dos cidadãos na definição de suas prioridades a serem encaminhadas pelo Estado, aqui representado no município.

Segundo JACOBI (1990) e LeAL (2003), o aprofundamento da democracia se dá com a ampliação da participação da população, o que assegura a legitimidade e responsabilidade nas decisões em nome da

\section{Método}

O estudo é uma pesquisa qualitativo-analítica, ajustada a processos e procedimentos de registro, análise e correlação dos dados. Diante do conjunto de fins estabelecidos, e considerando as características do objeto investigado que determina em larga medida o perfil da pesquisa, apoiamo-nos em procedimentos metodológicos recomendados por RichaRdSON (1999) e BARDIN (2004), que, a esse respeito, propõem a articulação e classificação categorial ou temática investigando o que elas têm em comum.

Com base nas recomendações acima, procederam-se aos seguintes encaminhamentos:

a) determinação da população que, nesse caso, trata-se do universo dos municípios da RMR em um total de 14 experiências de gestão pública municipal;

b) elaboração do instrumento de coleta de dados; nesse caso, um roteiro com um conjunto de 40 questōes e subquestões orientadoras da captação de informaçôes alusivas aos objetivos do estudo;

c) validação do instrumento de coleta com o objetivo de verificar a pertinência interna e externa, tanto quanto a aproximação teórica e conceitual como quanto à pertinência e adequação da linguagem utilizada no instrumento. coletividade. Nessa participação, expõem-se diversos conceitos de democracia.

Nesse estudo, uma das considerações importantes feitas referiu-se aos limites decorrentes dos "novos" modelos de gestão desportiva da Região Metropolitana do Recife em seu processo de descentralização de políticas, pois estes, apesar de se apresentarem com formatos concebidos como mais modernos, contudo, ainda exibem ausência de políticas públicas multissetoriais à medida que a prática local nessa área, que pode ser denominada de agenda ou calendário de competiçôes, é majoritariamente de futebol, acrescida de experiências de escolinhas desportivas com ênfase nessa modalidade, e também revelam, dificuldade em conceber a descentralização como descentramento de políticas e açôes.

Nesse aspecto, nossa pesquisa aponta para o fato de que, apesar de existirem procedimentos para tomadas de decisões com formulação em critérios técnicos multissetoriais e descentralizados, isso, todavia, não tem implicado a RMR em divisão/ redistribuição da gestão desportiva e, sobretudo, em diversificação de políticas nessa área.

Posteriormente, realizaram-se entrevistas com os sujeitos gestores do desporto municipal da RMR. Com base em TRIVIÑos (1987), deram-se os seguintes passos para a realização das entrevistas:

a) obtenção de informações políticas, geográficas e socioeconômicas;

b) dimensão ética: informação aos entrevistados, por escrito, quanto à intenção do estudo, com a finalidade de obter a autorização para realização da entrevista;

c) o registro das entrevistas, por precaução, deu-se pela utilização de dois gravadores que funcionaram simultaneamente durante as entrevistas.

Entrevistaram-se 14 gestores de desporto da RMR considerando os procedimentos pertinentes e apropriados para o interesse do estudo, tal como propõe BARDIN (2004) no que concerne à análise de conteúdo.

\section{Das respostas}

Segundo Richardson (1999) e BARDin (2004), toda pesquisa é organizada com o intento de responder a questões e elementos ainda não suficientemente respondidos por estudos anteriores. Suas opções políticas, suas referências e preferências nas 
respostas procuradas dizem respeito ao seguinte sistema de perguntas temáticas:

a) com que critérios se formulam as políticas desportivas?; b) Como são efetivadas as políticas desportivas?; c) Quais são os procedimentos para a avaliação de políticas desportivas?; d) Quais são os projetos, programas e ações oferecidos pela gestão?

\section{Do percurso \\ para obtenção das informações}

Utilizou-se um roteiro semiestruturado, com a finalidade de produzir informaçôes e conhecimentos referentes à descentralização, à gestão em si e às respectivas consequências e impacto.

\section{Transformando informações em dados}

As informações, uma vez recolhidas e cuidadosamente organizadas, passaram à condição de tema de dados e contribuíram para as inferências necessárias operacionalmente e considerando a aproximação deste estudo com os indicativos de BARDIN (2004) quanto à análise de conteúdo, processo a que se submeteram os dados sistematizados. Para tanto, os procedimentos comuns a esse tipo de pesquisa, que se utilizam neste estudo, são: a) pré-análise, em que foram selecionadas as informações que realmente importam para o estudo; b) fase de sistematização e elaboração de um procedimento preciso para o desenvolvimento do trabalho, de acordo com RICHARDSON (1999); c) análise com base em um suporte teórico que possa indicar tendências, opções, limites e vicissitudes.

\section{Da análise do conteúdo sistematizado}

O procedimento para a análise do conteúdo manifesto ou identificado, após a realização dos procedimentos anteriormente descritos, apoia-se nas contribuições de BARDIN (2004) e RICHARDSON (1999), que indicam a necessidade de isolamento dos temas extraídos dos textos, articulando-os com o problema pesquisado. Assim, foram escolhidos e organizados os temas principais e os secundários em uma tabela, o primeiro devendo especificar o conteúdo da parte em análise, e o segundo, especificá-lo.

\section{Da organização dos dados}

O procedimento decorrente da organização dos dados de valores, segundo a teoria, indica que as tabulações originárias da intensidade dos conteúdos podem revelar com maior nitidez e fidedignidade, uma vez que considerará a direção da afirmação/discurso.

\section{Resultados e discussão}

\section{Procedimento de descentralização}

O processo de descentralização, verificado nas experiências de Políticas Públicas Desportivas da RMR (com exceções), não é necessariamente um procedimento conceitual voltado para a materialização da democracia, e sim uma opção metodológica relacionada com a desconcentração, que diz respeito ao encaminhamento de procedimentos que levem programas e ações do setor desportivo das prefeituras analisadas aos bairros e às comunidades em situação de risco social, determinada pela própria demanda; municípios muito extensos, de difícil acesso, muito mais no período de chuva, com comunidades carentes, em que as questões sociais são predominantes.

Os discursos sobre a descentralização da RMR, na maioria, não têm aderência na perspectiva indicada por LEAL (2003, p.25), em que a "relação entre governo local e participação democrática estaria caminhando em uma espécie de 'autogestão', que possibilita a visualização da multiresponsabilização [...]”, conforme é possível perceber na análise dos quadros.

Assim, considerando a dinâmica histórica, MourA (1996) afirma que o processo de descentralização ocorre em dois importantes momentos: o primeiro com a relação entre o governo local, o governo central e a sociedade, e o foco na participação do povo e na descentralização intraurbana. $\mathrm{O}$ segundo momento foi notadamente na década de 90, em que se focava a dimensão econômica como estratégia para o desenvolvimento.

Tais procedimentos podem efetivamente dificultar a efetivação de uma cultura cívica no setor de desporto, que os sujeitos interessados possam ter maior intervenção no que concerne à participação em arenas decisórias, com sugestões críticas, fiscalização da efetivação e de recursos, de modo que, com a participação, o próprio Estado e o governante possam se fortalecer diante da sociedade segundo a perspectiva de PUTNAM (2002). No entanto:

Para que algum passo a mais seja dado, hoje teríamos de ter do ponto de vista do governo 
uma decisão política de ampliar a estrutura da Diretoria de Esportes. Sem isso, ficamos muito presos e limitados, não vendo perspectiva de ampliar e descentralizar as ações, porque é preciso pessoal. A alternativa que estamos utilizando é a de convênios e de conquista de parceria com o governo federal, mais recentemente com o governo estadual [...]. (Gestor entrevistado).
Outra evidência é que na estrutura federativa brasileira o município é ativo produtor de política e de experiências singulares de gestão pública. Tal evidência pode ser encontrada nos estudos de LUBAMBO (2000) e DinIZ (1997). Mais especificamente, destaca-se o estudo de AmAral (2003).

Na RMR dá-se de forma centralizada, quase absolutamente (QUADRO 1).

QUADRO 1- Identificação de tendência do tema descentralização.

\begin{tabular}{|c|c|c|c|}
\hline \multirow{2}{*}{$\begin{array}{l}\text { Gestores/ } \\
\text { Cidades }\end{array}$} & \multicolumn{2}{|c|}{ Descentraliza } & \multirow{2}{*}{\begin{tabular}{|c|} 
Comentários \\
Justificativa do gestor
\end{tabular}} \\
\hline & Sim & Não & \\
\hline 1 & & $\mathrm{x}$ & O município é extenso e carente. \\
\hline 2 & $\mathrm{x}$ & & É nucleado; necessidade de ampliar o acesso. \\
\hline 3 & & $\mathrm{x}$ & $\begin{array}{l}\text { Sistema em elaboração; indefinição, existe conflito nas atribuições das políticas de } \\
\text { esporte e lazer. }\end{array}$ \\
\hline 4 & & $\mathrm{x}$ & Intenção de desenvolver projetos por região. \\
\hline 5 & & $\mathrm{x}$ & Existe falta de vontade política das gestões em geral. \\
\hline 6 & & $\mathrm{x}$ & As ações são divididas por região. \\
\hline 7 & & $\mathrm{x}$ & Dificuldade de captação de recursos humanos necessários para expandir e descentralizar. \\
\hline 8 & & $\mathrm{x}$ & $\begin{array}{l}\text { Esforça-se para descentralizar e fazer as pessoas de Itapissuma jogar entre si para } \\
\text { manter o intercâmbio. }\end{array}$ \\
\hline 9 & & $\mathrm{x}$ & Existem núcleos. No futebol, descentralizam; já o fulsal é centralizado. \\
\hline 10 & & $\mathrm{x}$ & $\begin{array}{l}\text { Estrutura pequena para a demanda; déficit de pessoal. Há grande centralização no } \\
\text { pólo urbano. }\end{array}$ \\
\hline 11 & & $\mathrm{x}$ & $\begin{array}{l}\text { Centralizado ao mesmo tempo que descentraliza. Utiliza procedimentos de subsí- } \\
\text { dios. Algumas associações realizam eventos esportivos com o apoio da Prefeitura. }\end{array}$ \\
\hline 12 & & $\mathrm{x}$ & Centralizado. Limite financeiro e de infraestrutura, foco nos estudantes. \\
\hline 13 & & $\mathrm{x}$ & $\begin{array}{l}\text { Centralizam-se no Gabinete, que desenvolve ou dá as diretrizes para o trabalho, que } \\
\text { é executado nos locais. }\end{array}$ \\
\hline 14 & & $\mathrm{x}$ & $\begin{array}{l}\text { Centralizado. A educação e o esporte se interligam. Ênfase na educação, com o } \\
\text { objetivo de formar bons atletas. }\end{array}$ \\
\hline
\end{tabular}

Contudo, e como já dito acima, ao se analisar o discurso desses agentes de forma geral, observa-se que o conceito teórico de descentralização é compreendido e praticado como desregionalização, desconcentração. Com uma exceção, o Recife, conforme se pode identificar. Sendo assim, verifica-se na descentralização: a) baixo estabelecimento de diálogo com a população; b) baixa cultura cívica da sociedade em relação às políticas públicas desportivas.

Participação direta da população nas diretrizes: encaminhamento eavaliação da política de desporto, limites identificado

Quanto ao tema referente à participação, a identificação de necessidade de serviços por parte dos gestores, em larga medida, é o que indica os procedimentos referentes à participação popular. Supóe-se que o nível de organização e a presença de líderes em dadas comunidades são os elementos pelos quais se identificam as necessidades, uma vez que o estudo não identificou nenhum outro procedimento de característica técnico-metodológica de identificação de demandas. Assim sendo, quanto mais se planeja e se executa, mais aumentam as demandas.

Alguma exceção atribui-se ao chamado orçamento participativo, já referido, em que se discute e se elegem prioridades em uma arena especialmente constituída para esse fim, ou seja, as prioridades do conjunto de políticas a serem efetivadas pelo Executivo municipal, bem como a prestação de contas do que havia sido encaminhado. 
De forma geral e em algumas especificidades, realizam-se fóruns de esportes na cidade, onde se procura contato com as associações esportivas para cadastrá-las, como estratégia de aproximação desses setores com a gestão, para juntos, em parceria, poder desenvolver a política das ações esportivas. No entanto: "Infelizmente não conseguimos desenvolver grande coisa por conta de impedimentos, como falta de recursos e por outros interesses." (Gestor entrevistado).

Os entrevistados afirmam que há processo participativo em sua gestão. No entanto, em uma análise mais detalhada, identifica-se que a participação não está em sua totalidade vocacionada para a perspectiva de maior deslocamento de poder dirigido à sociedade como (em última instância) uma ação que se constituiria em maior democratização e fortalecimento de uma cultura cívica, conforme PUTNAM (2002). Sendo assim, de acordo com todos os discursos, não existem arenas especificamente instituídas para debate e a decisão acerca de diretrizes para as políticas públicas desportivas; desse modo, tem-se que as políticas públicas desportivas da RMR são deliberadas de forma tradicional e centralizada, afastando o cidadão comum, que normalmente não tem voz nem poder nos processos decisórios; processos pelos quais não é possível exercitar a democracia participativa (QUADRO 2).

QUADRO 2 -Identificação de tendência do tema participação.

\begin{tabular}{|c|c|c|c|}
\hline \multirow{2}{*}{$\begin{array}{l}\text { Gestores/ } \\
\text { Cidades }\end{array}$} & \multicolumn{2}{|c|}{ Participação } & \multirow{2}{*}{$\begin{array}{l}\text { Comentários } \\
\text { Justificativa do gestor }\end{array}$} \\
\hline & Sim & Não & \\
\hline 1 & $\mathrm{x}$ & & A participação é toda dentro da demanda. \\
\hline 2 & $\mathrm{x}$ & & No OP; discutem sobre o poderia ser feito no esporte. \\
\hline 3 & $\mathrm{x}$ & & $\begin{array}{l}\text { Participa no esporte, OP, nos programas desenvolvidos. Cobram muito; quanto } \\
\text { mais se faz, maior é a demanda. }\end{array}$ \\
\hline 4 & $\mathrm{x}$ & & $\begin{array}{l}\text { A população participa. Houve o primeiro fórum de esportes na cidade. Mantém- } \\
\text { se contato com as associaçôes para cadastrá-las e aproximá-las da gestão. }\end{array}$ \\
\hline 5 & $\mathrm{x}$ & & Faltam fóruns específicos. \\
\hline 6 & $\mathrm{x}$ & & $\begin{array}{l}\text { A população comparece de forma sistemática às conferências. A Conferência de } \\
\text { Cultura vai-se repetir. }\end{array}$ \\
\hline 7 & $\mathrm{x}$ & & $\begin{array}{l}\text { Realizam reunião nos clubes municipais. O povo participa das discussões e da } \\
\text { elaboração do regulamento. }\end{array}$ \\
\hline 8 & $\mathrm{x}$ & & A população cobra a realização de eventos. \\
\hline 9 & $\mathrm{x}$ & & $\begin{array}{l}\text { A população participa só fazendo cobrança e como torcedor, mas a Prefeitura tem } \\
\text { dificuldade para atender. }\end{array}$ \\
\hline 10 & $\mathrm{x}$ & & $\begin{array}{l}\text { A população participa das reuniões com sugestão quanto às prioridades para } \\
\text { aplicação dos recursos. }\end{array}$ \\
\hline 11 & $\mathrm{x}$ & & $\begin{array}{l}\text { As pessoas ajudam, outras só criticam; não são críticas construtivas, é mais políti- } \\
\text { ca. Não realizam seminários. }\end{array}$ \\
\hline 12 & $\mathrm{x}$ & & $\begin{array}{l}\text { Realizam seminários para conscientizar os formadores de opinião e a população de } \\
\text { que eles têm voz ativa. Tudo é feito em parceria com a população. }\end{array}$ \\
\hline 13 & $\mathrm{x}$ & & Os pais e as mães ficam em contato; têm interesse de saber o que os filhos estão fazendo. \\
\hline 14 & $\mathrm{x}$ & & $\begin{array}{l}\text { A Diretoria de Esportes e a Prefeitura tomam as decisões e passam para a comuni- } \\
\text { dade. As mães têm confiança e liberam os filhos para participar das atividades. }\end{array}$ \\
\hline
\end{tabular}

Pela análise do QUADRO 2, o problema principal estaria na despolitização do setor desportivo, vindo a ser um órgão executor e não formulador como decorrência ou resultado de arenas, das quais pessoas da terceira idade, ambientalistas, representantes da saúde, da educação, da criança e do adolescente pudessem participar com a apresentação de suas demandas, debatendo e as defendendo.
Quanto à gestão, do ponto de vista da operacionalização de procedimentos que indiquem maior participação do conjunto da sociedade, percebe-se que ainda carece de fóruns específicos para que isso se estabeleça como rotina de trabalho. Contudo, os esforços verificados norteiam esforços que valorizam o diálogo com as comunidades. 
Em relação à gestão do desporto municipal, uma das formas institucionalizadas de se aproximar é por meio dos conselhos setoriais de políticas desportivas. No período de coleta desses dados, algumas eleições estavam sendo organizadas. Os conselhos setoriais de desporto - instituições de participação popular - têm, como visto, o papel de discutir, questionar, propor, avaliar, denunciar, reivindicar, indicar as demandas relativas ao desporto e lazer. Trata-se da formalização de arenas que contribuem para a rivalidade entre agentes interessados no desporto.

No caso da Região Metropolitana do Recife, todas as cidades organizaram as respectivas conferências, para, a partir de então, poderem eleger novos representantes a fim de apresentar e defender seus interesses no debate nacional. Assim como nos quadros anteriormente tratados, a aproximação não indica uma tendência; pelo contrário, parece uma ação sem consequências, determinada pela dimensão tênue da população em relação ao setor.

Assim, considerando a dinâmica histórica, MouRA (1996) afirma que o processo de descentralização ocorre em dois importantes momentos: o primeiro com a relação entre o governo local, o governo central e a sociedade e o foco na participação do povo e na descentralização intraurbana. $\mathrm{O}$ segundo momento foi notadamente na década de 90 , em que se focava a dimensão econômica como estratégia para o desenvolvimento.

Na TABELA 1, é possível verificar de forma mais aguda a tendência do conteúdo dos discursos quanto à descentralização. Para tanto, os indicadores "sim e não" foram utilizados, a fim de se verificar no final a tendência em relação ao tema descentralização e, consequentemente, o comentário que justifica a posição do gestor.

TABELA 1 - Índice de descentralização.

\begin{tabular}{ccc}
\hline \multicolumn{3}{c}{ Descentralização } \\
Sim & Não & $\%$ \\
\hline 1 & 13 & -99 \\
\hline
\end{tabular}

Tais procedimentos podem efetivamente dificultar a efetivação de uma cultura cívica no setor de desporto, que os sujeitos interessados possam ter maior intervenção no que concerne à participação em arenas decisórias, com sugestões críticas, fiscalização da efetivação e de recursos, de modo que, com a participação, o próprio Estado e o governante possam se fortalecer diante da sociedade segundo a perspectiva de PUTNAm (2002). No entanto:
Para que algum passo a mais seja dado, hoje teríamos de ter do ponto de vista do governo uma decisão política de ampliar a estrutura [...]. Sem isso, ficamos muito presos e limitados, não vendo perspectiva de ampliar e descentralizar as açōes, porque é preciso pessoal. A alternativa que estamos utilizando é a de convênios e de conquista de parceria com o governo federal, mais recentemente com o governo estadual [...]. (Gestor entrevistado).

Portanto, a TABELA 1 revela o indicativo de que a intervenção dos gestores da RMR dá-se de forma centralizada, quase absolutamente. Contudo, e como já dito acima, ao se analisar o discurso desses agentes de forma geral, observa-se que o conceito teórico de descentralização é compreendido e praticado como desconcentração. Com exceção. Sendo assim, verifica-se na descentralização:

a) um debate muito embrionário no campo das políticas de desporto;

b) baixa formação dos agentes gestores e baixíssima capacitação para os estabelecimentos de diálogo com a população;

c) baixa cultura cívica da sociedade em relação às políticas públicas desportivas.

\section{Participação direta da população nas diretrizes}

Uma parte significativa dos gestores concorda que algum avanço das políticas desportivas locais teria de haver do ponto de vista do governo, do chefe do Executivo local, a decisão política de ampliar a estrutura de gestão do esporte, com a contratação de mais pessoal, melhorias na infraestrutura de gerência e maior disponibilidade de recursos. Sem isso, fica-se limitado, sem perspectiva de ampliar e descentralizar as ações, porque é necessário pessoal e recursos materiais.

No entanto, identificou-se que a participação não está em sua totalidade vocacionada para a perspectiva de maior deslocamento de poder dirigido à sociedade como uma ação que se constitui em maior democratização e fortalecimento de uma cultura cívica, conforme PUTNAm (2002).

Os procedimentos de participação identificados não são formalmente constituídos para esse fim, ou seja: espaço para debates, articulação, convencimentos e alianças, mas sim para procedimentos quase "informais", ou seja:

a) reuniōes informativas em que o ouvinte tem pouca ou quase nenhuma margem de intervenção; 
b) aparteamento de projetos "prontos" em que os sujeitos interessados são convidados para discutir pontualmente esse ou aquele item do projeto, a exemplo do regulamento de competições;

c) participação indireta, em que setores específicos (crianças e adolescentes, terceira idade, pessoas com necessidades especiais, entre outros) encaminham suas demandas ao setor de desporto.

De acordo com JACOBI (1990) e LEAL (2003), o aprofundamento da democracia se dá com a ampliação da participação da população (TABELA 2), o que assegura a legitimidade e responsabilidade nas decisões em nome da coletividade. Nessa participação, expõem-se diversos conceitos de democracia. Reitere-se que a descentralização necessariamente não é uma condição para que se efetive a democracia; antes, ela contribui para que a cultura cívica se fortaleça.

TABELA 2 - Índice de participação popular.

\begin{tabular}{ccc}
\hline \multicolumn{3}{c}{ Participação } \\
Sim & Não & $\%$ \\
\hline 14 & 0 & 100 \\
\hline
\end{tabular}

Por último, em relação ao índice de participação indicado pelo conteúdo dos discursos dos gestores, observa-se como dito anteriormente, a "ausência" de institucionalização de espaços políticos para participação popular nas decisões das políticas desportivas, com poucas exceções de quatro das 14 experiências investigadas, o que pode indicar pouco "empowerment" da população.

Segundo Moroni (2005), observa-se que a importância de ampliar os mecanismos de participação popular diz respeito ao fato de que os partidos políticos, via processo eleitoral, já não são suficientes para garantir, como forma única, a participação mais ampla da democracia representativa.

\section{Conclusão}

Levando em conta as entrevistas realizadas, não é possível afirmar que em rigor haja políticas públicas desportivas nas 14 cidades pesquisadas. Nesse sentido, a ação política está circunscrita ao desenvolvimento de torneios, campeonatos, escolinhas desportivas, especialmente de futebol, com apoio limitado a atletas no seu deslocamento para participar de eventos desportivos no interior ou fora do Estado.
O QUADRO 3 e a TABELA 3 sintetizam a relação entre a gestão desportiva e a população via sociedade civil organizada.

QUADRO 3 - Conselhos mais citados.

\begin{tabular}{|l|c|}
\hline Conselhos mais citados & número \\
\hline Conselho do Esporte & 2 \\
\hline Conselho do Idoso & 2 \\
\hline Conselho de Saúde & 4 \\
\hline Conselho de Cultura & 2 \\
\hline Conselho Tutelar & 1 \\
\hline Conselho de Educação & 3 \\
\hline
\end{tabular}

TABELA 3 - Índice de proximidade da população por meio dos conselhos.

\begin{tabular}{ccc}
\hline \multicolumn{3}{c}{ Proximidade da população } \\
Sim & Não & $\%$ \\
\hline 11 & 3 & +97 \\
\hline
\end{tabular}

Observa-se, no QUADRO 3, que, diferentemente de outras políticas públicas (saúde, educação, crianças e adolescentes), há praticamente ausência de conselhos de desportos nas cidades da RMR, de modo que, de outros conselhos, sejam encaminhadas demandas pontuais correspondentes a políticas de outros setores.

A TABELA 4 revela de forma mais efetiva o comportamento das prefeituras da RMR em relação aos investimentos em desporto.

TABELA 4 - Tendência de receita e investimentos.

\begin{tabular}{ccc}
\hline \multicolumn{3}{c}{ Receita e investimento } \\
Positivo & Negativo & Intermediário \\
\hline 5 & 4 & 5 \\
\hline
\end{tabular}

Sendo assim, as políticas públicas desportivas da RMR redundam em atendimentos mínimos e focais, o que sinaliza ou para uma característica de desresponsabilização ou para a baixa prioridade dessas políticas por parte do poder local.

Sendo assim, a afirmação de que o desporto "ocupa” espaço importante na agenda pública local não encontrou aderência nos dados obtidos na grande maioria dos municípios da RMR. Na verdade, os 
discursos recorrentes justificam que as políticas públicas desportivas não se materializam em decorrência da limitação financeira dos municípios.

Se a prioridade ao desporto tivesse consistência, mesmo diante da limitação financeira comum, esses municípios poderiam efetivar os novos formatos de gestão local com bastante eficiência, tais como o orçamento participativo, fóruns de debate e parcerias públicas e privadas.

Infere-se, então, que a prioridade ao desporto é dada quando se realizam eventos geradores de visibilidade, tanto para a cidade como para o chefe do Executivo, em específico, perante seu eleitorado, e na dimensão econômica, em que estão compreendidos os interesses dos meios de comunicação e dos promotores dos eventos desportivos.

Se bem que o discurso dos gestores saliente o chamado desporto social, educativo, a materialização desse conteúdo mostrou-se frágil no que concerne aos procedimentos de universalização e democratização, ou seja, o de que todos possam ter acesso social ao desporto. Em síntese, observados o conteúdo dos discursos, verificou-se que:

1) não é possível afirmar com rigor a existência de políticas públicas de descentralização desportiva na totalidade das experiências das cidades investigadas na RMR;
2) Quase não há políticas públicas desportivas. Em seu lugar, temos projetos pontuais desarticulados e carentes de planejamento. Sobretudo, há déficit de decisão política, e quando ocorre, é fora da arena;

3) Os itens acima ajudam a refutar a universalização da política desportiva da RMR como uma determinação constitucional do Pacto Federativo brasileiro. As entrevistas apontam a existência de muitas dificuldades enfrentadas tendo em vista a falta de empenho do chefe do Executivo local para alocar recursos suficientes, o que suscita intervençōes focais em detrimento da universalização.

Desse modo, todos esses fatores, aliados à baixa capacidade de argumentação em defesa do desporto como política pública, contribuem para que a política desportiva permaneça agudamente secundária, primeiro, no que diz respeito ao papel dos setores sociais e ao grau de participação exercido no controle social de gestão desportiva, pois, os dados demonstram uma tendência negativa a esse tema. Também, salvo exceções, mesmo nas experiências relativas a orçamentos participativos, argumentou-se sobre o grau de maturidade política para a efetivação formal de controle da política pública desportiva.

\section{Abstract}

Sports management and public policy in metropolitan Recife

This article aims to reflect on the management of sports developed in the Metropolitan Region of Recife by analyzing the discourse of managers from 14 cities that make up this area, stressing social and cultural perceptions that influence these practices developed around these policies. To this end, we work with the methodology of content analysis in order to examine how far cultural bias interfere on the actual development of sports public policies decentralized and committed to the scope of a participatory citizenship.

UnITERMS: Management; Public policy; Sport.

\section{Resumen}

Deporte gestión y políticas públicas en la región metropolitana de Recife

En este artículo se reflexiona sobre la gestión de los deportes desarrollados en la Región Metropolitana de Recife a analizar el discurso de los gestores de 14 ciudades que conforman esta área, haciendo hincapié en que estas percepciones influyen en las prácticas socio-culturales o desarrollados en torno a estas políticas. Para ello, trabajamos con la metodología de análisis de contenido con el fin de examinar hasta qué punto los prejuicios culturales interferem con el desarrollo real de las políticas públicas deportivas descentralizadas de los comprometidos con el alcance de una ciudadanía participativa.

Palabras Clave: Gestión; Políticas públicas; Deporte. 


\section{Referências}

ABIB, S.W. Participação popular no planejamento urbano: uma construção teórico-metodológica. In: CONGRESSO BRASILEIRO DE CADASTRO TÉCNICO MULTIFINALITÁRIO, 8., 2008, Florianópolis. Anais... Florianópolis: Universidade Federal de Santa Catarina, 2008.

AMARAL, S.C.F. Políticas públicas de lazer e participação cidadã: entendendo o caso de Porto Alegre. Campinas, São Paulo. Tese (Doutorado em Educação Física) - Faculdade de Educação Física, Universidade Estadual de Campinas, Campinas, SP, 2003.

ANDRADE, I.A.L. Políticas e poder: o discurso da participação. São Paulo: Ad Hominem, 1996.

AZEVEDO, F. A cultura brasileira. 6. ed. Rio de Janeiro: Editora da UFRJ, 1996.

BARDIN, L. Análise de conteúdo. Lisboa: Edições 70, 2004.

BARZELAY, M. Breaking through bureaucracy: a new vision for managing in government. Berkeley: The University of California Press, 1992.

CASTRO, J.D. Regulação em saúde: análise de conceitos fundamentais. Sociologias, Porto Alegre, v.4, n.7, p.122-36, 2002. CONSTANTINO, J.M. Desporto, política e autarquia. Lisboa: Livros Horizonte, 1999.

COUTO, C. O processo decisório municipal como instrumento da autonomia: consideraçôes a partir do caso paulistano. In: MELO, M.A. Reforma do Estado e mudança institucional: agenda de pesquisa nos anos 80 e 90. Recife: Massangana, 1999. DINIZ, E. Crise, reforma do estado e governabilidade: Brasil, 1985-1995. Rio de Janeiro: Fundação Getúlio Vargas, 1997. JACOBI, P. Administração municipal, descentralização e participação: uma agenda de indagaçôes no contexto da transição. São Paulo: Cedec, 1990.

LEAL, S.M.R. Fetiche da participação popular: novas práticas de planejamento, gestão e governança democrática no Recife-Brasil. Recife: Edição do Autor, 2003.

. Modelos de descentralização política na gestão local: os novos formatos na década 90. In: LACERDA, N.; LEAL,

S. M. R. (Org.). Relação público-privado: do local ao global. Recife: Universidade Federal de Pernambuco, 1996.

Para além do Estado: tendências, limites e alcance das novas formas de gestão urbana a nível local. Tese (Doutorado em ) - Instituto de Economia, Universidade Estadual de Campinas, Campinas, 1994.

LOBO, T. Política social e descentralização. In: MINISTÉRIO DA PREVIDÊNCIA E ASSISTÊNCIA SOCIAL. A política social em tempo de crise: articulação institucional e descentralização. Brasília: Cepal, 1990.

LUBAMBO, C.W. O desempenho da gestão pública e seus determinantes: uma análise em municípios do Nordeste. 1999. Tese (Doutorado em Sociologia) - Programa de Pós-Graduação em Sociologia, Universidade Federal de Pernambuco, Recife, 2000. Políticas públicas e capacidade de Estado: reforma do Estado e capacidade de gestão pública nos municípios nordestinos. In: MELO, M.A. Reforma do Estado e mudança institucional: agenda de pesquisa nos anos 80 e 90 . Recife: Massangana, 1999.

MELO, M A. Crise federativa, guerra fiscal e hobbesianismo municipal: efeitos perversos da descentralização? In: OLIVEIRA, M.A.G. Política e contemporaneidade no Brasil. Recife: Bagaço, 1997.

Federalismo e política social: as vicissitudes da descentralização. In:LACERDA, N.; LEAL, S.R. (Org.). Relação público-privado: do local ao global. Recife: UFPE, 1996.

Reforma do Estado e mudança institucional: agenda de pesquisa nos anos 80 e 90. Recife: Massangana, 1999.

MENEZES, V.G. Gestão democrática, participação popular e políticas públicas: a experiência de Camaragibe. Recife: Bagaço, 2005.

Gestão de políticas públicas desportivas municipais: análise da região metropolitana do Recife-PE, Brasil, no período de 2002-2008. Porto. 2009. Tese (Doutorado) - Universidade do Porto, Porto, 2009.

. Políticas públicas para esporte/lazer. Recife: Bagaço, 2002.

MODESTO, P. Participação popular na administração pública: mecanismo de operacionalização. Revista Eletrônica de Direito do Estado, Salvador, n.2, 2005. Disponível em: <http://www.direitodoestado.com/revista/REDE-2-ABRIL-2005PAULO\%20MODESTO.pdf>.

MORONI, J.A. Participamos, e daí? Observatório da Cidadania, 2005. Disponível em: http://www.aracati.org.br/portal/ pdfs/13_Biblioteca/Textos\%20e\%20artigos/participacao_Moroni.pdf>. Acesso em: 26 nov. 2006.

MOURA, S. Redes de ação pública na gestão local: tendências atuais. In: LACERDA, N.; LEAL, S.M.R. (Orgs.). Relação público-privado: do local ao global. Recife: Universidade Federal de Pernambuco, 1996.

PIRES, G. Mudança social e gestão do desporto. Ludens, Lisboa, v.15, n.4, p.21-63, 1995.

. A organização faz a organização da organização. Ludens, Lisboa, v.13, n.3/4, p.2-40, 1993. 
PIRES, G.; SARMENTO, J. P. Conceito de gestão do desporto: novos desafios, diferentes soluções. Revista Portuguesa de Ciências do Desporto, Porto, v.1, n.1, p.88-103, 2001.

PUTNAM, R.D. Comunidade e democracia: a experiência da Itália moderna. 3. ed. Rio de Janeiro: Fundação Getúlio Vargas, 2002.

RICHARDSON, R.J. Pesquisa social: métodos e técnicas. 3. ed. São Paulo: Atlas, 1999.

SARMENTO, J.P. Desporto universitário? Porto: Associação de Estudantes da Faculdade de Ciências do Desporto e de Educação Física/Universidade do Porto, 2002.

TOBAR, F. O conceito de descentralização: usos e abusos. Planejamento e Políticas Públicas, Brasília, n. 5, p. 31-51, 1991. TRIVIÑOS, N.S.A. Introdução à pesquisa em ciências sociais. São Paulo: Atlas, 1987.

VALLA, V.V. Sobre participação popular: uma questão de perspectiva. Cadernos de Saúde Pública, Rio de Janeiro, v.14, p.7-18, 1998. Suplemento 2.

VIANA, A. Política educacional e participação popular: um estudo sobre esta relação no município de Camaragibe-PE. 2003. Dissertação (Mestrado em Educação) - Faculdade de Educação, Universidade Federal de Pernambuco, Recife, 2003. VIEIRA, A.L.B. A influência dos fatores organizacionais na prática do desporto em escolas públicas da cidade do Recife-PE-Brasil. 2004. Dissertação (Mestrado em Ciência do Desporto/Gestão Desportiva) - Faculdade de Ciências do Desporto e de Educação Física, Universidade do Porto, Porto, 2004.

ENDEREÇO

Aurenéa Maria de Oliveira Departamento de Fundamentos Sócio-Filosóficos da Educação Centro de Educação Universidade Federal de Pernambuco Av. Prof. Moraes Rego 1235 50670-901- Recife - PE - BRASIL e-mail: aurenea@yahoo.com.br
Recebido para publicação: 12/ 09/2011

Revisado: 27/02/2012

Aceito: 19/03/2012 